\title{
A new species of Zographetus Watson, 1893 (Lepidoptera: Hesperiidae) from Sikkim, eastern Himalaya, India
}

\author{
TARUN KARMAKAR ${ }^{1,2,4}$, SONAM WANGCHUK LEPCHA ${ }^{2,3,5}$, DIPENDRA NATH BASU ${ }^{1,2,6}$ \\ \& KRUSHNAMEGH KUNTE ${ }^{1,2}$ * \\ ${ }^{1}$ National Centre for Biological Sciences, Tata Institute of Fundamental Research, GKVK Campus, Bellary Road, Bangalore 560065 , \\ India \\ ${ }^{2}$ Indian Foundation for Butterflies, Bangalore 560 097, India \\ ${ }^{3}$ Noom Panang village, under Passingdang Saffo GPU, P/O Sangkalang, Upper Dzongu, North Sikkim District, Sikkim 737116, India \\ ${ }^{4}$ ○ https://orcid.org/0000-0001-9085-4891 \\ 5 ๑ https://orcid.org/0000-0003-1376-6526 \\ ${ }^{6}$ ○ https://orcid.org/0000-0002-1529-0931 \\ "Corresponding author. "”rushnamegh@ncbs.res.in; @ https://orcid.org/0000-0002-3860-6118
}

\begin{abstract}
A new species, Zographetus dzonguensis sp. nov., is described based on three male specimens from Upper Dzongu, North Sikkim District, Sikkim, India. The new species is closely similar to Z. pangi from Guangdong and Z. hainanensis from Hainan, China, from which it is distinguished based on the following combination of external characters: (a) forewing with the white spot at the base of space M3 being sharply pointed at the inner edge and conspicuously more elongated, and (b) on underside of hindwing, all chocolate-brown spots being smaller, in $\boldsymbol{Z}$. dzonguensis sp. nov. compared with both $Z$. pangi and Z. hainanensis. In $Z$. dzonguensis sp. nov., the male genitalia may be distinguished as follows: (c) tegumen and uncus are almost equal in length, (d) the dorsal outline of tegumen is relatively flat, and (e) saccus is distinctly bent upward as angle between vinculum and saccus is more acute than in Z. pangi and Z. hainanensis.
\end{abstract}

Key words: Himalaya biodiversity hotspot, species discovery, species description, butterfly taxonomy

\section{Introduction}

The genus Zographetus Watson, 1893 (Hesperiidae: Hesperiinae) is distributed in the Oriental Region from the Himalaya and north-eastern India through southern China, Indo-China, and the Malay Peninsula to the Philippines, Sulawesi and the Lesser Sunda Islands (Xue et al. 2019). Along with the type-species, Isoteinon satwa de Nicéville, [1884] (now Z. satwa (de Nicéville, [1884])), 13 species are known so far (Xue et al. 2019). In India, two species are recorded: (a) Z. satwa (de Nicéville, [1884]), which occurs from Kumaon eastward into the Himalaya and NE India, extending to Myanmar, Indo-China, Thailand, Peninsular Malaysia, Sumatra and Java, and (b) Z. ogygia (Hewitson, [1866]), which occurs in India in the Western Ghats, Eastern Himalaya and NE India, extending to Myanmar, IndoChina, Thailand, Peninsular Malaysia, Sumatra, Java, and Borneo (Corbet et al. 1992; Ek-Amnuay 2012; Evans 1932, 1949; Inayoshi 2020; Kunte et al. 2021; Maruyama 1991; Sondhi et al. 2013; Sondhi \& Kunte 2018a; b). Recently, we discovered a population of a new species of Zographetus in Sikkim, India, which is described below. This species is very similar to two recently described species, Z. pangi Fan \& Wang, 2007 from Nanling National Nature Reserve, Guangdong and Z. hainanensis Fan \& Wang, 2007 from Yinggeling, Hainan, China (Fan et al. 2007), with which the new species is compared.

\section{Materials and methods}

SWL saw a total of 18 individuals of the species in Namprikdang village, North Sikkim District, Sikkim, India, at an 
altitude of approx. 870m, in August and September 2020 and 2021, of which five individuals were photographed. Of these, we collected three males (IBC-BM770, IBC-BM771 and IBC-BM772). We pinned and dried two specimens (IBC-BM770 and IBC-BM771; Fig. 1), and preserved one specimen (IBC-BM772) in 100\% molecular-grade ethanol for molecular work. The specimens are deposited in the Biodiversity Lab Research Collections of National Centre for Biological Sciences (NCBS), Tata Institute of Fundamental Research, Bengaluru (=Bangalore), India (http://biodiversitycollections.in).

We dissolved extraneous tissue using $10 \% \mathrm{KOH}$ to dissect the male genitalia of paratypes IBC-BM770 and IBC-BM772 (Fig. 2), and then preserved the genitalia in anhydrous glycerol at room temperature.

We photographed pinned specimens using a Canon 1200D DSLR camera body with Canon $60 \mathrm{~mm}$ macro lens. We photographed the dissected male genitalia with Leica DFC425 digital camera mounted on a Leica M250 C stereomicroscope. All the genitalia images were focus-stacked with Leica application suite software.

We took morphometric measurements (wing and antennal length) from images of pinned specimens using ImageJ ver. 1.53F (Schneider et al. 2012) — an open source Java image-processing program.

Terminology for venation and genitalia follow Kunte et al. ( 2019).

\section{Taxonomic description}

\section{Zographetus dzonguensis sp. nov. Kunte, Karmakar \& Lepcha}

(Figs. 1-3)

Holotype (Fig. 1): Voucher code IBC-BM771. 0 . The type locality is Namprikdang village, North Sikkim District, Sikkim, India (27.518403, 88.531640). Approx. $870 \mathrm{~m}$ asl. Collected by Sonam Wangchuk Lepcha on 3 Sept. 2021, with permission from the local panchayat (village council) and the Dept. of Forest, Environment and Wildlife Management, Govt. of Sikkim. Preserved dry, pinned, deposited in the Biodiversity Lab Research Collections at NCBS.

Paratypes: Voucher codes IBC-BM770 (Fig. 1, adult, pinned and preserved dry; Fig. 2, genitalia) and IBCBM772 (preserved in 100\% molecular-grade ethanol; Fig. 2, genitalia). 0 . Collection data same as the holotype.

Description of the male holotype (Fig. 1): Forewing length: $13 \mathrm{~mm}$. Length of antenna: $8 \mathrm{~mm}$. Head and thorax covered with yellow scales; abdomen ventrally ringed with yellow and black or dark brown, with the tip black. Legs yellow. Antennae black, with a pale midshaft, especially on the underside.

Dorsal side: Forewings dark brown, covered sparsely in ochreous scales. A medium-sized white spot at the lower angle of the cell-end; a larger white spot in $\mathrm{CuA} 1$ just below the cell-end spot; and a narrower, more elongated white spot from near the origin of v. CuA1 in M3. These three spots are adjacent to each other, separated by dark veins. Another smaller white spot in M1. Pale orange-yellow hair tuft along the basal half of the dorsum. Hindwings unmarked.

Ventral side: Forewing dark brown, the basal $2 / 3^{\text {rd }}$ of costa and subapical area covered in bright yellow scales. The distal $1 / 3^{\text {rd }}$ of costa is narrowly chocolate brown, termen is more broadly bordered chocolate-brown. White spots around the cell similar to dorsal side. Hindwing bright yellow. A large, irregular chocolate-brown spot at cellend. Two smaller chocolate-brown spots in the centre of spaces CuA1 and M3. An even smaller, obscure brown spot at the origin of v. Sc. Wing borders more broadly chocolate-brown at the tornus compared to that on the forewing, tapering towards apex. Cilia paler yellow. The pinned specimen has much of the yellow scales on forewing and those on hindwing costa lost during collection of the specimen.

Description of the paratypes, and intraspecific variation (Fig. 1, 3): The two paratypes collected, and other specimens photographed in nature, were very similarly patterned to the holotype. The subtle variation was in the form of the size of chocolate-brown spots and borders on the underside: (a) on hindwing, chocolate-brown spots in spaces $\mathrm{M} 3, \mathrm{CuA} 1$ and, when present, in $\mathrm{CuA} 2$, being variable in size, (b) the size and shape of the chocolatebrown cell-end spot on hindwing, and (c) variation in the width of the chocolate-brown terminal margin on both the wings.

Male genitalia: Paratypes (IBC-BM770 and IBC-BM772, Fig. 2): Tegumen dorso-ventrally broad and dorsal outline almost flat. Uncus long, slender, and the narrow distal tip curved downward. Major sub-uncal processes are absent, which is a characteristic of the genus Zographetus. Saccus is slender in the lateral view, and the rounded tip of saccus is gradually bent upward. Valva undulated along the dorsal margin, ending in a costal process. The 
costal process is triangular, and the rounded distal tip is produced upward above dorsal margin of corona in the lateral view. Corona is smooth and rounded at the distal and ventral edges, whereas the dorsal margin is serrated with a hump-shaped harpe near the inner margin. Aedeagus consists of a proximal subzonal sheath, which is narrow proximally and broad near the annulus. Subzonal sheath is almost $1.5 \times$ longer than the distal suprazonal sheath. Juxta is U-shaped and broad.

Female: Unknown.

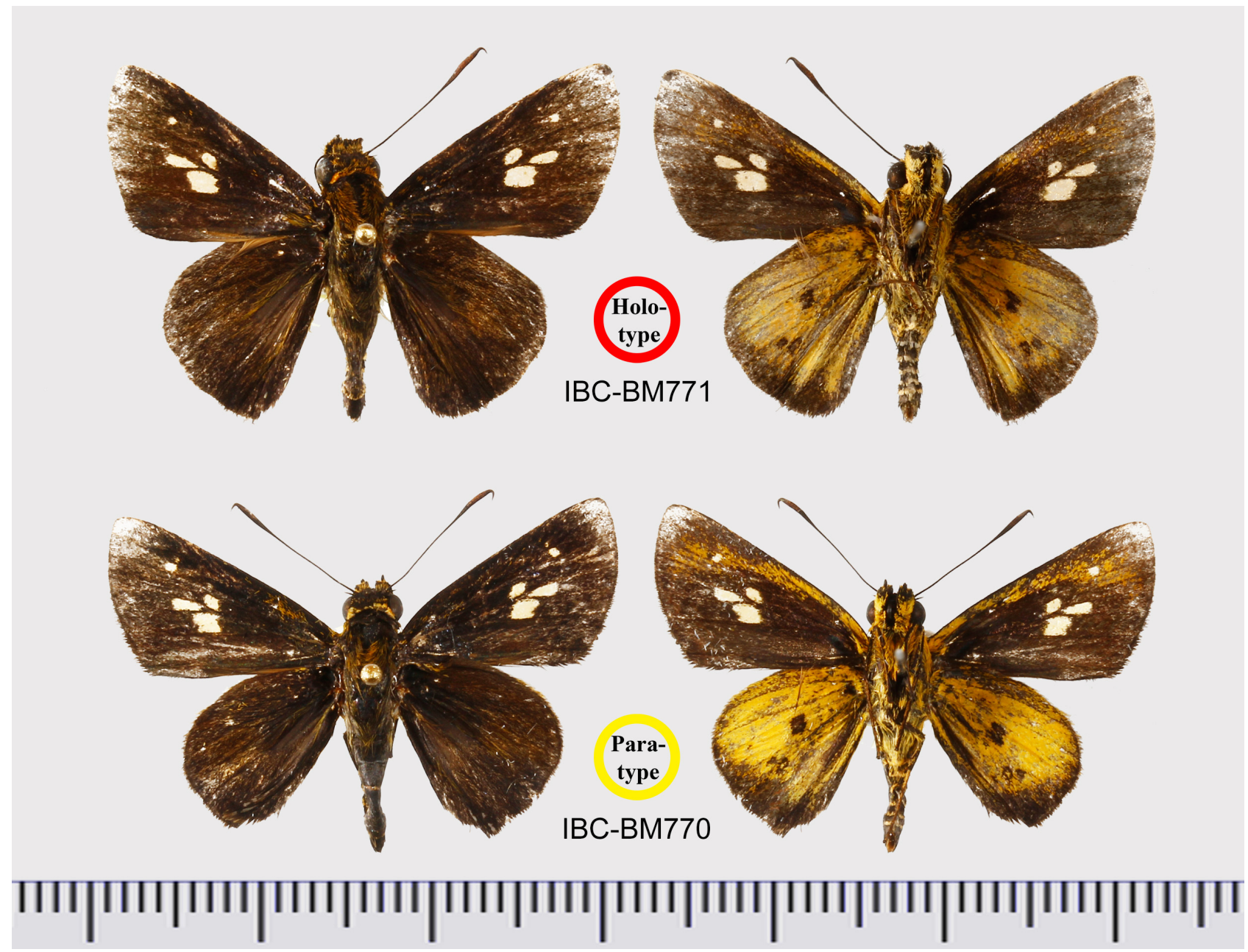

FIGURE 1. Type specimens of Zographetus dzonguensis sp. nov. A millimetre scale is at the bottom.

Diagnosis: Externally, Z. dzonguensis sp. nov. is very similar to Z. pangi and Z. hainanensis. The main differences are in the shape of the cell spot and spot in M3 on the forewing, and underside colouration of the hindwing. In $Z$. dzonguensis sp. nov., the spot at the base of space M3 is sharply pointed at the inner edge and conspicuously more elongated compared with $Z$. pangi and $Z$. hainanensis. On the forewing of $Z$. pangi, the spots at cell-end and in $\mathrm{CuA} 1$ are larger. On the underside of hindwing, all chocolate-brown spots are larger in both Z. pangi and $Z$. hainanensis compared with $Z$. dzonguensis sp. nov.

Zographetus dzonguensis sp. nov. is easily distinguished from the Indian congeners by largely bright yellow wings on the underside, with only narrow chocolate brown borders on both wings. In Z. satwa and Z. ogygia, underside of hindwing is much more heavily marked with chocolate-brown, with purple sheen $(Z$. satwa $)$ or spots (Z. ogygia) on the outer half of the wing (Kunte et al. 2021).

Zographetus dzonguensis sp. nov. is distinguished based on the male genitalia from Z. pangi and Z. hainanensis as follows: in $Z$. dzonguensis sp. nov., tegumen and uncus are almost equal in length, whereas in $Z$. pangi and $Z$. hainanensis uncus is longer than the tegumen (Fan et al. 2007). The dorsal outline of tegumen is relatively flat in Z. dzonguensis sp. nov., whereas it is prominently more convex in Z. pangi and Z. hainanensis. In the lateral view, vinculum is more acutely curved, and saccus is distinctly bent upward in $Z$. dzonguensis sp. nov. compared to the other two species. 


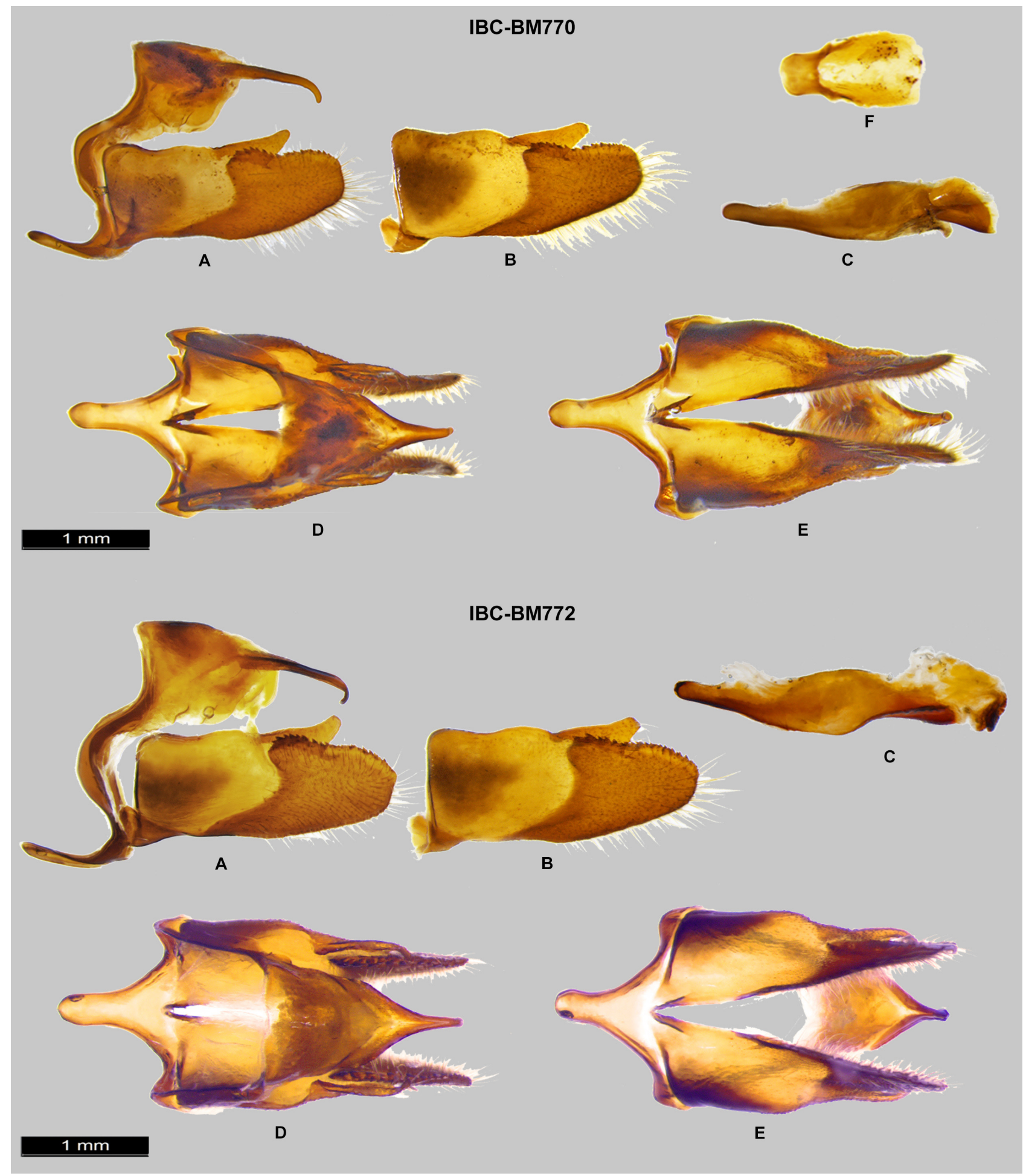

FIGURE 2. Male genitalia of paratypes of Zographetus dzonguensis sp. nov. A. lateral view of genital capsule, B. valva, C. aedeagus, D. dorsal view of genital capsule, E. ventral view of genital capsule, F. juxta. In IBC-BM770, 'A' shows the outside of the right valve, and ' $B$ ' shows inside of the left valve (left valve was separated from the genital capsule and then photographed). In IBC-BM772, 'A' shows inside of the left valve, and 'B' shows outside of the right valve (right valve was separated from the genital capsule and then photographed).

Absence of sub-uncal processes, and presence of distinct costal process and serrated dorsal margin of corona, are common in all the three species.

The three taxa compared here, $Z$. dzonguensis sp. nov., Z. pangi and Z. hainanensis, have largely similar colouration, spotting pattern and the male genitalia. However, they are distinguished by subtle and constant 
differences, similar in degree to the previously described species in this group (Fan et al. 2007). Unfortunately, these geographically non-overlapping taxa are nowhere common and therefore the collected series are limited, and the comparative molecular data are unavailable. Therefore, it is difficult at present to further comment on their systematic positions at species and subspecies levels. We have not yet been able to generate sufficient molecular data on the three species to resolve these matters, which should be taken up in the future.

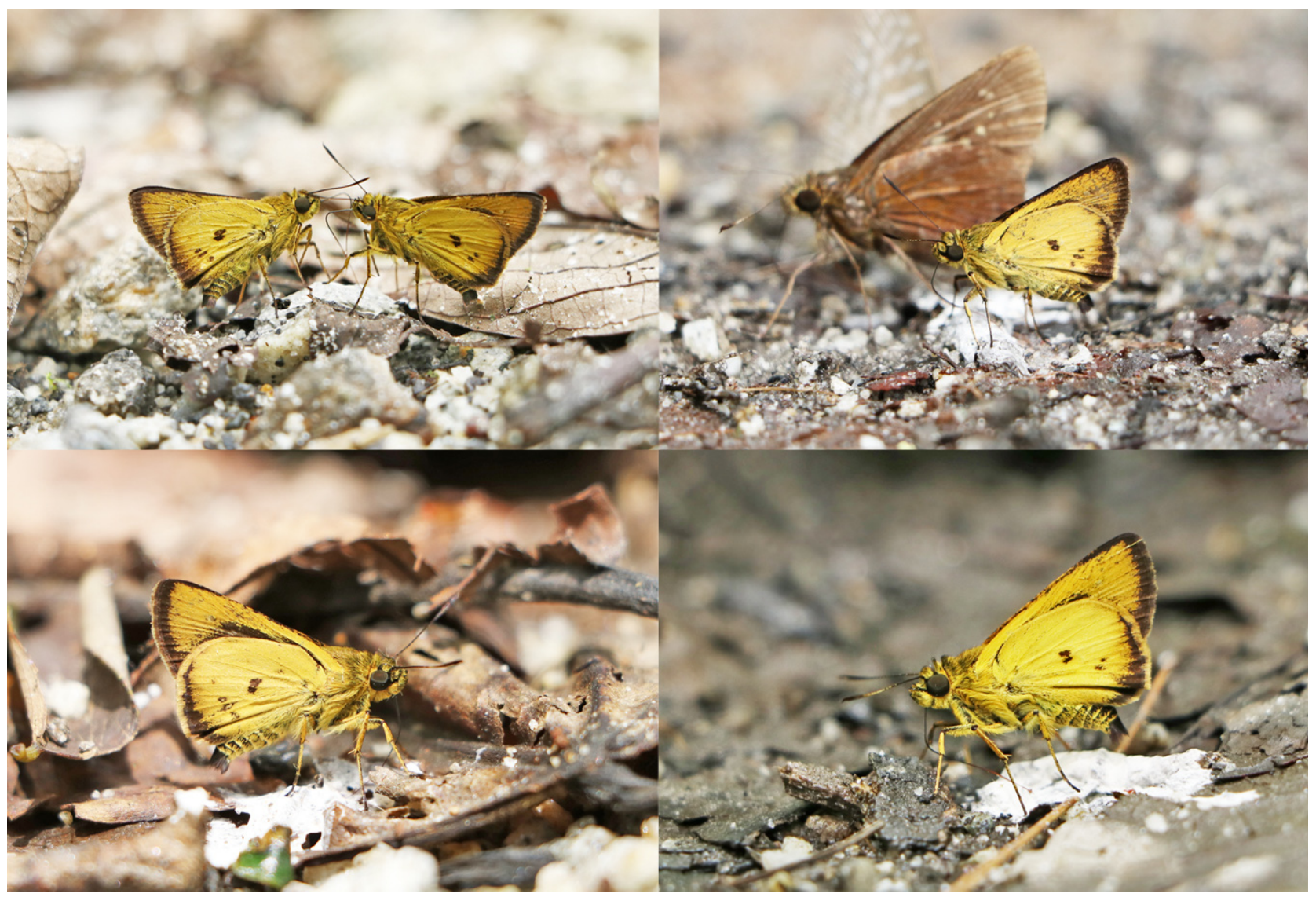

FIGURE 3. Zographetus dzonguensis sp. nov. in life. All individuals were photographed at Namprikdang playground, Dzongu, North Sikkim District, Sikkim, India in August-September 2020 and 2021. Photographs (C) Sonam Wangchuk Lepcha.

Etymology: The new species is named after the type locality of Dzongu in Sikkim. This is a stronghold of the Lepcha - the people of Sikkim - to whom the description of this species is dedicated.

Proposed English name: We propose the English name 'Chocolate-bordered Flitter' for this species based on the chocolate-coloured termens of both the wings on the ventral side.

Distribution: The species is known so far only from the type locality of Dzongu in North Sikkim District. We expect it to be more widely distributed in other parts of Sikkim and adjoining Nepal, northern West Bengal, Bhutan, Arunachal Pradesh and south-eastern Tibet, at similar elevations.

Status, habitat, and habits: Based on the current limited experience, the species appears to be very local and seasonal, occurring below $1,000 \mathrm{~m}$ asl in mixed evergreen and semi-evergreen broad-leafed forests of North Sikkim District. So far as known, it is active on sunny days from early morning to mid-day. It has largely been observed feeding on bird droppings in shaded stream-beds (Fig. 3).

Flight period: The first sightings of this species were in August 2016. Recent sightings were from the last week of August to mid-September 2020 and 2021. Based on this limited information, the species appears to be univoltine in Sikkim.

Larval host plants and early stages: Unknown. The only known larval host plant recorded for Zographetus in India appears to be Aganope thyrsiflora (Fabaceae), for Zographetus ogygia ogygia (Hewitson, [1866]) (Nitin et al. 2018). Zographetus dzonguensis sp. nov. is expected to feed on related plant genera and species.

Sympatric Zographetus: We have not yet seen any other species of Zographetus at the type locality.

As more information on this species accumulates, it will be made available on the species page of the Butterflies of India website (https://www.ifoundbutterflies.org/zographetus-dzonguensis). 


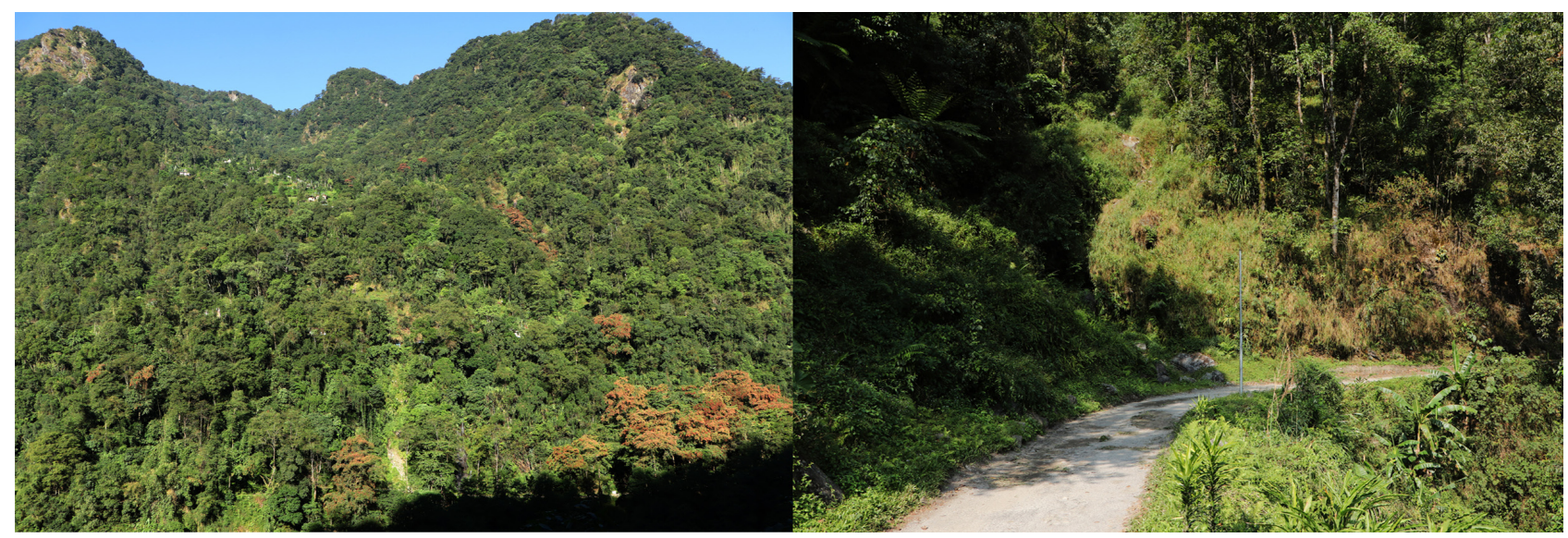

FIGURE 4. Forests surrounding Namprikdang playground, Dzongu, the habitat of Zographetus dzonguensis sp. nov.

\section{Acknowledgements}

We thank Xiao-ling Fan for advice on Zographetus, and for providing high-resolution images of the holotype of Z. hainanensis; Hideyuki Chiba and two anonymous reviewers for taxonomic advice and detailed comments that improved this manuscript; and Pemday Lepcha (Panchayat of Noom Panang village, Upper Dzongu), Norden Z. Bhutia (Range Forest Officer, Dzongu Range), Nosang Muringla Limboo and Sonam Pintso Sherpa for support during field work. The specimens were collected under a research and collection permit (no. 78/GOS/F\&ED/BD-R2015/180, dated 4 Aug. 2021) from the Dept. of Forest, Environment \& Wildlife Management, Govt of Sikkim, for which we thank Karma Loday Bhutia (Forest \& Environment Minister, Govt of Sikkim), Tshering Wangyal Bhutia (Additional Political Secretary to Honourable Chief Minister), M. L. Srivastava, IFS (Principal Chief Conservator of Forest), and Chewang Tashi Bhutia, IFS (Assistant Conservator of Forest, Research and Extension). Additional permissions were obtained from the panchayat (village council) of Noom Panang Village, Passingdang Saffo GPU, Dzongu. The work was funded by an NCBS Research Grant to KK and support of the Department of Atomic Energy, Government of India, under project nos. 12-R\&D-TFR-5.04-0800 and 12-R\&D-TFR-5.04-0900 to TIFR/NCBS.

\section{References}

Corbet, A.S., Pendlebury, H.M. \& Eliot, J.N. (1992) The Butterflies of the Malay Peninsula. 4th revised edn. Malayan Nature Society, Kaula Lumpur, 595 pp.

Ek-Amnuay, P. (2012) Butterflies of Thailand. $2^{\text {nd }}$ revised edn. Baan Lae Suan Printing \& Publishing Co., Bangkok, 943 pp.

Evans, W.H. (1932) The Identification of Indian Butterflies. $2^{\text {nd }}$ revised edn. Bombay Natural History Society, Mumbai, 454 pp.

Evans, W.H. (1949) A Catalogue of the Hesperiidae from Europe, Asia and Australia in the British Museum (Natural History). British Museum (Natural History), London, 502 pp. https://doi.org/10.5962/bhl.title.105941

Fan, X.L., Wang, M., Chen, L.S. \& Zeng, L. (2007) The genus Zographetus Watson (Lepidoptera: Hesperiidae) in China, with the description of two new species. Entomological News, 118, 296-302. https://doi.org/10.3157/0013-872X(2007)118[296:TGZWLH]2.0.CO;2

Inayoshi, Y. (2020) A Check List of Butterflies in Indo-China, Chiefly from Thailand, Laos \& Vietnam. Available from: http:// yutaka.it-n.jp (accessed 30 November 2021)

Kunte, K., Basu, D.N. \& Girish Kumar, G.S. (2019) Taxonomy, Systematics, and Biology of Indian Butterflies in the $21^{\text {st }}$ Century. In: Ramani, S., Mohanraj, P. \& Yeshwanth, H.M. (Eds.), Indian Insects. CRC Press, Boca Raton, Florida, pp. 275-304.

https://doi.org/10.1201/9780429061400-16

Kunte, K., Sondhi, S. \& Roy, P. (2021) Butterflies of India. Version 3.17. Indian Foundation for Butterflies. Available from: https://www.ifoundbutterflies.org (accessed 30 November 2021)

Maruyama, K. (1991) Butterflies of Borneo. Vol. 2 (2). Hesperiidae. Tobishima Corp., Tokyo, 84 pp.

Nitin, R., Balakrishnan, V.C., Churi, P.V., Kalesh, S., Prakash, S. \& Kunte, K. (2018) Larval host plants of the butterflies of the 
Western Ghats, India. Journal of Threatened Taxa, 10, 11495-11550.

https://doi.org/10.11609/jott.3104.10.4.11495-11550

Schneider, C.A., Rasband, W.S. \& Eliceiri, K.W. (2012) NIH Image to ImageJ: 25 years of image analysis. Nature Methods, 9, 671-675.

https://doi.org/10.1038/nmeth.2089

Sondhi, S. \& Kunte, K. (2018a) Butterflies and Moths of Pakke Tiger Reserve. $2^{\text {nd }}$ revised edn. Titli Trust (Dehradun), National Centre for Biological Sciences (Bengaluru), and Indian Foundation for Butterflies, Bengaluru, 242 pp.

Sondhi, S. \& Kunte, K. (2018b) Butterflies of Uttarakhand - A Field Guide. Bishen Singh Mahendra Pal Singh (Dehradun), Titli Trust (Dehradun), National Centre for Biological Sciences (Bengaluru), and Indian Foundation for Butterflies, Bengaluru, 310 pp.

Sondhi, S., Kunte, K., Agavekar, G., Lovalekar, R. \& Tokekar, K. (2013) Butterflies of the Garo Hills. Samrakshan Trust (New Delhi), Titli Trust (Dehradun), and Indian Foundation for Butterflies, Bengaluru, 200pp.

Xue, G., Li, M., Li, X., Xie, G., Chen, K. \& Li, J. (2019) A new species of the genus Zographetus Watson, 1893 from China (Lepidoptera: Hesperiidae). Zootaxa, 4629 (2), 255-262.

https://doi.org/10.11646/zootaxa.4629.2.7 